\title{
RESILIÊNCIA FAMILIAR E CONJUGAL NUMA PERSPECTIVA PSICANALÍTICA DOS LAÇOS
}

\author{
Pierre Benghozi* \\ Tradução de Sandra Teixeira Marques**
}

\section{Resumo}

Neste texto abordamos a questão do dilaceramento traumático como a expressão de um desmalhe dos continentes psíquicos individuais, familiares e comunitários. Consideramos a resiliência familiar como a capacidade da própria família de reconstruir os laços psíquicos. Para ilustrar a conceituação teórica da malhagem numa perspectiva psicanalítica do laço, tomamos a rede como objeto metafórico. Na clínica, propomo-nos lançar mão de dispositivos que permitam trabalhar a capacidade da família e consideramos que uma psicoterapia unicamente individual conduz a uma evolução clínica limitada.

Palavras-chave: trauma, resiliência, laço, violência

\begin{abstract}
FAMILIAR AND CONJUGAL RESILIENCE IN A PSYCHOANALYTIC PERSPECTIVE OF THE PSYCHICAL BONDS

In this text we approach the question of the traumatic dilaceration as the expression of an unweaving of the individual, familiar and communitarian psychic continents. We consider familiar resilience as the capacity of the family to reconstruct by itself the psychical bonds. To illustrate the theoretical conceptualization of weaving in a psychoanalytic perspective of the bond, we take the net as a metaphorical object. In the clinical practice, we propose to use devices
\end{abstract}

* Doutor em Psiquiatria; Professor da Universidade de Paris V; Vice-presidente da Sociedade Francesa de Psicoterapia Psicanalítica de Grupo; Membro da Sociedade Francesa de Terapia Familiar Sistêmica; Diretor do Serviço de Psiquiatria da Criança, do Adolescente e da Família de Hyères; Presidente da Comissão Nacional sobre Violência do Conselho Superior do Ministério do Trabalho e da Solidariedade da França.

** Mestranda em Psicologia Clínica pela PUC-Rio. 
which contribute to enhance the capacity of the family as a whole, and we consider that individual psychotherapy alone leads to a limited clinical evolution.

Keywords: trauma, resilience, bond, violence

A psicopatologia mobilizada pelo rumor da violência nos leva a elaborar uma clínica do real. Numerosos trabalhos se organizam em torno do traumatismo e de suas conseqüências sobre a vida psíquica, afetiva e social. Somos confrontados com o impensável, o indizível e o inominável. O acento foi colocado sobre a denúncia da conspiração do silêncio, sobre a importância da revelação, do reconhecimento do traumatismo, sobre a verificação dos efeitos. A singularidade do vivido traumático a partir de um mesmo acontecimento conduz a diferenciar trauma e traumatismo em função da capacidade de gestão individual e grupal do acontecimento: como tentar pensar não apenas a atualidade, mas o além do dilaceramento traumático. Nossa proposta, neste texto, é abordar alguns elementos de resposta, desenvolvendo o aforismo: "após o dilaceramento, a remalhagem!".

Isto nos convidará a encarar a hipótese do dilaceramento como expressão de uma desmalhagem dos continentes psíquicos individuais, familiares e comunitários e a reparação como um trabalho de remalhagem dos laços. O paradigma da violência é visto aqui como o ataque contra o humano pela arma da humilhação. Explicitaremos, neste sentido, a noção de resiliência familiar e comunitária numa perspectiva psicanalítica do laço e numa abordagem ética do laço humano.

A noção da resiliência familiar propriamente dita é aquela que concerne aos recursos do grupo familiar por ele mesmo em conjunto e aos dos membros que o constituem. Ela é objeto de uma pesquisa específica enriquecida pela experiência e pela reflexão teórico-clínica no campo das terapias familiares.

Definimos a resiliência familiar como a capacidade de malhagem dos laços psíquicos. Dito de outro modo, a capacidade de desmalhar e remalhar, de desconstruir e reconstruir o laço, entendido como laço psíquico de filiação e afiliação. O primeiro nos liga, no nível genealógico, a nossos ascendentes e nossos descendentes, o segundo nos define horizontalmente enquanto sujeitos com nossos pertencimentos.

Para ilustrar nossa conceitualização teórica da malhagem numa perspectiva psicanalítica do laço, tomamos a rede como objeto metafórico (Benghozi, 1994). O emaranhado dos laços psíquicos de filiação e dos laços de afiliação forma as malhas, cujo agenciamento constitui uma malhagem. Este objeto metafórico tem, assim, a particularidade de permitir uma visualização em três dimensões: o conjunto desta malhagem dos laços vai, então, construir uma rede, ou seja, um con- 
tinente psíquico, pois, precisamente, o estudo da resiliência é abordado com o seguinte questionamento: “o dilaceramento, e após o dilaceramento?”. De qual dilaceramento se trata? Em nossa perspectiva, trata-se de um dilaceramento dos laços. $\mathrm{O}$ dilaceramento caracteriza a desmalhagem dos laços psíquicos de filiação e afiliação. Essa desmalhagem pode ser "catastrófica" em um duplo sentido: no sentido da teoria da catástrofe de Thom (1989), quando o dilaceramento tende a rasgar sem interrupção, e igualmente no sentido das angústias catastróficas que o psicanalista Bion descreve (1965).

\section{UM ATAQUE AOS LAÇOS}

A desmalhagem catastrófica é, então, um ataque aos laços. A esse dilaceramento corresponde uma efração dos continentes psíquicos. Neste sentido, a resiliência familiar é uma clínica de remalhagem dos laços, quer dizer, uma clínica da efração dos continentes psíquicos grupais. Estamos, assim, implicados pelo que denominamos de feridas do narcisismo grupal. Elas reenviam fundamentalmente às problemáticas da identidade. Nós as incluímos junto com a efração traumática, a psicose, a psicossomática, as condutas aditivas e a expressão das passagens ao ato incestuosas e suicidas. Essas manifestaçôes traduzem, clinicamente, as modalidades defensivas de gestão de uma problemática do continente psíquico grupal e genealógico. A construção do sintoma é, então, com o portasintoma, uma tentativa de cerzir o dilaceramento, que tende a se propagar espontaneamente.

\section{UMA CRIATIVIDADE ALTERNATIVA}

Como, então, responder à questão "após o dilaceramento?”. Isto nos leva à investigação dos fatores que favorecem um trabalho de remalhagem dos laços rompidos. O objetivo não é, então, na perspectiva psicanalítica grupal e familiar, a erradicação do sintoma, mas a procura de uma criatividade alternativa à da produção do sintoma para restaurar a credibilidade da capacidade familiar. Nesta perspectiva, o continente não é compreendido unicamente como continente individual, mas como um continente grupal familiar e genealógico. A resiliência comunitária coloca em jogo o continente grupal comunitário. A resiliência familiar é naturalmente mobilizada no processo de crescimento individual e no ciclo de vida grupal familiar e genealógico.

A construção do laço de aliança conjugal é uma forma de remalhagem recíproca dos continentes familiares das famílias de origem de cada cônjuge. $\mathrm{Na}$ 
medida em que a malha é tecida sobre uma trama que une laço de filiação e laço de afiliação, a construção de um laço afiliativo permite gerar uma abertura do continente genealógico secundário para uma dor do laço de filiação. Esta é a função da malhagem afiliativa terapêutica. A teoria da malhagem genealógica abre perspectivas de recursos evolutivos constantes em situaçóes em que outros poderiam se decidir pela fatalidade de um destino inexorável. Na clínica, nos interrogamos sobre os dispositivos necessários para poder trabalhar a capacidade familiar. Uma prática psicoterapêutica unicamente individual nos conduz a evoluçōes clínicas limitadas, pois foram precisamente os limites dos cuidados que concernem ao traumatismo, às adições e à psicose que nos levaram a inventar novos dispositivos de trabalho psíquico graças aos dispositivos de acolhimento e de cuidados grupais, familiares e institucionais.

Propomo-nos o seguinte aforismo: o laço não é a relação (Benghozi, 1999). Com efeito, uma pessoa pode se situar claramente em relação a seu pai do ponto de vista do laço de filiação e ter conflitos relacionais com ele. Inversamente, uma outra pessoa pode ter uma excelente qualidade relacional com seu pai e com sua mãe e estar, do ponto de vista do laço, numa problemática de sofrimento particular. Deste modo, seu laço de filiação pode ser tisnado por um segredo. É o que ocorre na situação do segredo de uma adoção precoce ocultada à criança.

A particularidade do laço é a de ser o suporte da transmissão psíquica consciente e inconsciente. No nível genealógico, distinguimos a transmissão intergeracional e a transmissão transgeracional. Na primeira, o patrimônio psíquico familiar é recebido por uma geração, memorizado, historizado, transformado, elaborado e transmitido à nova geração. $\mathrm{Na}$ segunda, o material psíquico familiar é encaixado, segundo a expressão de Faimberg (1988), transmitido em estado bruto, sem ter sido metabolizado.

As problemáticas do laço são, assim, sempre problemáticas da transmissão psíquica. Podemos, então, colocar a seguinte questão: "a capacidade de resiliência se transmite?" - e pesquisar, então, as modalidades de transmissão nos níveis inter e trans-geracional.

\section{RuMO A NOVAS REPRESENTAÇÕES}

Como se mobiliza a resiliência familiar numa terapia de família? Temos precisado que a construção do laço terapêutico é, em si mesmo, uma malhagem afiliativa. Um novo continente psíquico grupal se co-constrói na terapia, associando família e terapeutas. Esse novo continente alternativo pode, então, acolher um processo de transformação psíquica que estava anteriormente em pane. Isto 
supõe uma disponibilidade para esta criatividade, liberada de toda tentativa do terapeuta de dominar o processo de mudança. As competências elaborativas intersubjetivas familiares abrem a via de novas representações. Como se organizar para estar suficientemente disponível para a mobilização das resiliências familiares e comunitárias? Como, então, pensar o lugar do terapeuta enquanto co-construtor do espaço psíquico do continente grupal terapêutico?

\section{RESILIÊNCIA FAMILIAR E COMUNITÁRIA E TRABALHO DE RITUALIZAÇÃO}

O trabalho sobre o ritual e sobre a ritualização é essencial para construir o espaço terapêutico. O laço é ritualizado, e o ritual assegura a transmissão do mito fundador do grupo de pertencimento. $\mathrm{O}$ mito se define como o conjunto das crenças partilhadas pelos membros do grupo: ele define, assim, os limites foradentro do pertencimento grupal. Essas crenças se estruturam em torno de valores de referências. No nível tópico, elas se referem ao ideal do eu do grupo de pertencimento familiar e comunitário. Com o mito fundador, o ideal do eu organiza as fronteiras de interioridade e de exterioridade do continente psíquico grupal, do laço de inclusão e do laço de exclusão e da identidade de pertencimento. Enquanto a culpabilidade é transgressão com respeito ao supereu, a vergonha é enfraquecimento frente ao ideal do eu. Consideraremos aqui o trabalho de ritualização como uma forma paradigmática de resiliência, o que permite sobreviver ao traumatismo fundamental da humilhação, à violência destrutiva de um ataque à dignidade do humano. A violência humilhante é simbolicida ${ }^{1}$, destruidora do laço de pertencimento do sujeito à comunidade dos humanos. $\mathrm{O}$ ataque contra $\mathrm{a}$ dignidade é um ataque contra o humano enquanto humano. Esta ritualização é uma organização seqüencial de uma prática intersubjetiva repetitiva, codificada no tempo e no espaço, segundo a ordem do rito do sistema de pertencimento. $\mathrm{O}$ trabalho de ritualização é uma modalidade de gestão da humilhação. Ele se inscreve como um verdadeiro significante formal de transmissão do "sagrado". O sagrado está aqui entre aspas, na medida em que transcende o religioso e religa (religare em latim) sagrado e laico... A partir daí, efetivamente, o trabalho de ritualização vai reunir, no nível da intersubjetividade e do conjunto das crenças, aquilo que funda o laço do sujeito humano enquanto pertencente à comunidade dos humanos.

\section{UMA POSIÇÃO ÉTICA}

Toda violência se caracteriza pela humilhação. O paradigma da violência é a humilhação destruidora do que funda o sujeito enquanto humano. A violência 
humilhante é simbolicida. Sua arma é a desmetaforização dessubjetivante. É uma forma insidiosa de ataque simbolicida contra o laço, como um vírus da informática que seria destruidor dos referenciais organizadores da trama da escrita. O que nos fundamenta enquanto terapeutas não é justamente o que nos conduz não a uma capacidade técnica, mas a uma posição ética? A posição ética é, para nós, aquilo que caracteriza nossa própria capacidade de indignação. Isto exprime nossa capacidade de empatia em relação à dignidade humana, quando esta é ameaçada ou violada. Esta posição ética nos parece fundamental. Delage (2001) sublinha, aproximando-se da teoria do apego de Bowlby (1984), a importância "do dar e do receber” na concepção da ética relacional de Boszormenyi Nagy (1986). Esta postura ética e esta empatia em relação ao humano serão aprendidas? Talvez sim, no encontro. Cyrulnik (1996) define a resiliência no encontro; é uma maravilhosa definição, na medida em que se trata de um encontro do humano com o humano.

\section{A RitualizaÇÃo DO PERDÃo}

Efetivamente, a empatia com o humano parece ser a melhor prevenção para tratar a ferida da humilhação. Depois de anos de pesquisa sobre a psicoantropologia da vergonha e da humilhação, propomo-nos pensar a ritualização jurídica como uma modalidade de gestão da culpabilidade e a ritualização do perdão como um modelo de gestão da vergonha e da humilhação.

\section{O VAZio E A FALTA: A ESTRATÉGIA DO ENGANO}

Encontramos este dilaceramento em todas as formas de influência, de tormento, qualquer que seja o contexto. Reparar o dilaceramento é gerir a brecha do continente rompido e não tentar cobrir a ferida. É como se confrontar com a catástrofe do vazio sem perseguir inexoravelmente a repetição aditiva do engano. Chamamos de estratégia do engano à construção de sintomas que escapam ao vazio, tentando preencher a falta. Em outros termos, a sintomatologia do engano é aquela que se propõe como estratégia inconsciente de gestão de uma falha de continente por uma estratégia de gestão do conteúdo. Ela se apresenta como um sintoma de preenchimento em lugar do que corresponde a um dilaceramento profundo do continente psíquico grupal e genealógico. Assim, por exemplo, alcoolismo, toxicomania, bulimia, anorexia e outros problemas de condutas aditivas traduzem tentativas de preenchimento do tonel das Danaides ${ }^{2}$. As filhas de Dânaos são condenadas a encher sem cessar o tonel perfurado. Nunca é suficiente; é necessário mais, ainda, sempre mais. É bem a espiral da dependência das adições 
toxicomaníacas. Diferenciamos, com vazio e falta, dois tipos de depressão. Uma traduz um vazio relacionado a uma psicopatologia de continente e, portanto, uma problemática da desmalhagem dos laços e da transmissão psíquica. A outra remete a uma falta como expressão de uma psicopatologia do conteúdo, ou seja, relativa aos avatares do trabalho de ligação psíquica. A relação com a perda é, então, objetal. Os continentes são confiáveis, mas a clínica traduz escoras no processo de elaboração como nas problemáticas neuróticas. Ao dilaceramento do continente corresponde o vazio, uma depressão melancólica, um afundamento, um dilaceramento narcísico, uma depressão identitária. Os alicerces narcísicos grupais do sujeito são hesitantes. Trata-se de uma problemática interpsíquica do laço que coloca em risco a separação e a individuação. Isto se manifesta no nível da imagem inconsciente do corpo individual e grupal familiar. As fronteiras do eu/não-eu, do fora/dentro, da inclusão/exclusão, da interioridade/exterioridade são fluídas. As angústias catastróficas são do tipo psicótico. $\mathrm{O}$ mecanismo de defesa principal é a identificação projetiva. Quando o navio afunda, trata-se sempre de depressão. Para que não seja o naufrágio cataclísmico do Titanic, é preciso escoar a água do barco furado.

$\mathrm{O}$ trabalho de remalhagem dos laços abre uma alternativa à desmalhagem catastrófica. A remalhagem afiliativa repara a desmalhagem do laço de filiação rompido. Vamos buscar dispositivos de apoio dos continentes recíprocos entre a dimensão humana individual, a do casal e a da família no espaço privado, a capacidade de um espaço social e de um espaço comunitário. Como se apóiam os continentes psíquicos do íntimo, do privado e do público na dinâmica de sustentação recíproca, como bonecas russas se contendo uma na outra, uma com a outra? A ritualização do laço é uma modalidade organizadora desses níveis intersubjetivos. Além das manifestações nostálgicas e fora de moda, podemos reconhecer, por exemplo, a importância das cerimônias, das manifestações de memória diante das placas comemorativas de eventos traumáticos da história de uma comunidade humana, diante da flâmula do soldado desconhecido tombado de uma morte anônima, onde se tenta ritualizar o luto metonímico do conjunto dos desaparecidos sem sepultura. Elas têm uma função econômica psíquica de resiliência familiar, social e comunitária para superar o traumatismo catastrófico e encontrar as fontes de uma nova vitalidade psíquica. No nível horizontal, o laço de rede permite sustentar a falência da capacidade familiar. A malhagem do continente de rede é sustentada, precisamente, a partir da problemática trazida pelo indivíduo "porta-vergonha familiar" (Benghozi, 1994), que é, ao mesmo tempo, portador ventríloquo de uma falha de simbolização na transmissão psíquica inter e transgeracional. Trata-se da expressão individual de um sofrimento grupal. $\mathrm{O}$ tra- 
balho de ritualização se coloca, particularmente, no jogo transferencial sobre o ritual, no setting terapêutico. É assim que os dilaceramentos dos continentes familiares se reatualizam por ataques contra o setting, como expressão de um ataque contra os laços. A resiliência é uma metáfora que permite continuar a sonhar.

\section{O RESPEITO RITUALIZADO DA CICATRIZ}

Retomando a metáfora do dilaceramento, sabemos que a sutura da ferida se elabora graças ao trabalho de cicatrização. A cicatrização faz crostas. Assim, muitas vezes, o que temos são os equivalentes psíquicos das crostas, que podem se mostrar repugnantes e dolorosas e até mesmo fontes de desgosto e humilhação. No entanto, sabemos a que ponto, como na cicatrização de uma grande queimadura, é necessário respeitar as crostas. É muito importante poder dar um tempo para que as crostas possam fazer seu próprio trabalho de cicatrização e cair, dando lugar a uma nova "pele" (Anzieu, 1999). O prêmio da reparação é ainda o respeito ritualizado pela cicatriz. Um certo número de intervençôes terapêuticas intempestivas trariam o risco de abrir novas feridas em vez de permitir o acompanhamento desta cicatrização. Efetivamente, essas crostas são, por vezes, vividas como insuportáveis, repugnantes, podendo se traduzir em uma desordem que provoca náuseas. Podemos ver, na clínica, como um certo número de pacientes se exprime e se protege através de sintomas repulsivos. É muito importante saber acompanhá-los e respeitá-los com suas crostas, suas próprias capacidades resilientes. A cicatriz é o suporte mnêmico da elaboração narrativa do trauma. Podemos apenas citar a importância do trabalho de malhagem afiliativa terapêutica, que permite, no encontro terapêutico, a emergência de um metagrupo terapêutico, que é mais do que a soma dos terapeutas e família em terapia. A narrativa, na terapia, dos pedaços recortados da história familiar dá acesso a um neocontinente narrativo alternativo ao continente familiar dilacerado. Isto permite conter a elaboração do processo inter e transpsíquico em suspenso. Nossa disponibilidade empática, a curiosidade empática em relação ao humano, é o que nos torna passíveis de escuta, no instante do encontro, de uma história que se conta, se sonha, se imagina e se reconta de várias formas, no presente, no processo terapêutico. Participamos, assim, da co-construção de um neocontinente narrativo, no lugar em que o continente psíquico faltoso estava rompido. O frescor familiar genealógico mobiliza, no pré-consciente familiar em sofrimento, o acesso a novas representaçōes, a uma nova circulação interfantasmática, a uma ruptura do congelamento emocional, à emergência de singularidades subjetivas plurais. Esse quadro grupal da terapia de 
família é mobilizador de uma resiliência familiar, ou seja, de uma capacidade psíquica transformadora e criadora do grupo familiar alternativa ao pavor.

Gostaríamos, para concluir, de insistir na dimensão ética, evocando uma citação que tomaremos de empréstimo a Lévinas (1996: 49) em A ética e o infinito: "Quando reencontro a face do outro, me julgo responsável".

\section{REFERÊNCIAS BIBLIOGRÁFICAS}

Anzieu, D. (1999). Le groupe et linconscient. Paris: Dunod.

Benghozi, P. (1994). Porte la honte et maillage des contenants généalogiques. Revue de Psychothérapie Psychanalytique de Groupe, 5. Paris: Érès.

Benghozi, P. (1999). Adolescence et sexualité, liens et maillage réseau. Paris: Harmattan.

Bion, W. (1965). Recherche sur les petits groupes. Paris: PUF.

Bowlby, J. (1984). Attachement et perte. Paris: PUF.

Boszormenyi Nagy, I. (1986). Between give and take. New York: Brunner-Mazel.

Cyrulnik, B. (1996). Un merveilleux malheur. Paris: Odile Jacob.

Delage, M. (2001). Répercussions familiales du traumatisme psychique. Conséquences pour une intervention thérapeutique. Revue francophone du stress et du trauma, 1 (4), 203-213.

Faimberg, H. (1988). À l' écoute du téléscopedes générations: pertinence psychanalitique du concept. Em Kaës, Faimberg, H. et coll. Transmission de la vie psychique entre générations (pp. 113-130). Paris: Dunod, 1993.

Lévinas, E. (1996). L'éthique et l'infini. Paris: Fayard.

Thom, R. (1989). Théorie des systèmes et théorie des catastrophes. Paris: Pistes.

\section{Notas}

1 Nota do Tradutor: No original, symbolicide. Neologismo, usado pelo autor, que busca traduzir o principal efeito do ataque à dignidade humana, qual seja, o assassinato do simbólico.

2 Nota do Tradutor: Na mitologia Grega, Danaides são irmãs que mataram seus esposos e foram condenadas a encher um vaso sem fundo por toda a eternidade.

Recebido em julho de 2005 Aceito para publicação em setembro de 2005 